\title{
Acquaintance, knowledge, and value
}

\author{
Emad H. Atiq ${ }^{1}$ (D) \\ Received: 18 June 2020 / Accepted: 7 September 2021 \\ (c) The Author(s), under exclusive licence to Springer Nature B.V. 2021
}

\begin{abstract}
Taking perceptual experience to consist in a relation of acquaintance with the sensible qualities, I argue that the state of being acquainted with a sensible quality is intrinsically a form of knowledge, and not merely a means to more familiar kinds of knowledge, such as propositional or dispositional knowledge. We should accept the epistemic claim for its explanatory power and theoretical usefulness. That acquaintance is knowledge best explains the intuitive epistemic appeal of 'Edenic' counterfactuals involving unmediated perceptual contact with reality (cf. Chalmers, in: Gendler, Hawthorne (eds) Perceptual experience, Oxford University Press, 2006). It explains the elusiveness of knowledge gained through new acquaintances. It coheres with the knowledge-like functional role of acquaintance in the special context of evaluative beliefs and evaluative reasoning, where the objects of acquaintance serve as evidence and inferential basis. And, finally, taking acquaintance to be knowledge is theoretically fruitful: it helps vindicate claims about the relationship between knowledge and concern for others we already find intuitive or outright accept. After developing a novel case for the epistemic claim, I respond to two familiar objections against it: namely, (1) that there are no pre-propositional, pre-conceptual cases of perceptual experience that remain epistemically relevant (Sellars in Empiricism and the philosophy of mind, Routledge, 1968, McDowell, in: Lindgard (ed) John McDowell: Experience, norm, and nature, Blackwell, 2008); and (2) that the category of knowledge appears gerrymandered once we add 'object' knowledge to the epistemological mix (Farkas, in: Knowles, Raleigh (eds), Acquaintance: new essays, Oxford University Press, 2019).
\end{abstract}

Keywords Perception - Knowledge by acquaintance $\cdot$ Evidence $\cdot$ Epistemic value . Evaluative reasoning

Emad H. Atiq

Eha47@cornell.edu

1 Law School and Sage School of Philosophy, Cornell University, 232 Hughes Hall, Ithaca, NY 14853, USA 


\section{Introduction}

The discussion is premised on the assumption that in perceptual experience agents bear a unique relation of acquaintance to the immediate objects of perception, which include the determinate shades of color, sound, and sensation (henceforth, 'the sensible qualities'). To be acquainted with a sensible quality — say, the redness of an apple or the pain of a headache-is to be aware of the quality in an especially direct and unmediated way, such that no fact, event, process, or property mediates one's awareness. ${ }^{1}$ Further characterization of the acquaintance relation may be difficult given its likely status as a metaphysical primitive, but the discussion to follow does not presuppose any more precise account of the relation's nature. Likewise, we can remain largely neutral on the precise nature of the sensible qualities. They may be mind-independent qualities of physical objects, so long as our conscious awareness of them is suitably direct as on contemporary versions of direct realism (see e.g., Johnston, 2004; Brewer, 2006). They may be qualities of a subject's sensory field or their experiences (Jackson, 1982), or non-physical particulars along the lines of sense-datum theory (Moore, 1910; Price, 1950; Robison, 1994; Russell, 1912). My use of 'object' is intended to be neutral between competing accounts of the nature of the sensible. What the discussion presupposes is that the sensible qualities, like a shade of red or a pain sensation, are real entities of which we are directly aware in perception, and that mental states with sensory phenomenology essentially involve such unmediated awareness.

Acquaintance, I argue, is knowledge (' $A \Rightarrow K$ '). ${ }^{2}$ More precisely, the mental state of being acquainted with a sensible quality counts intrinsically as an instance of knowledge, and not merely as a means of acquiring propositional or dispositional knowledge of the world. We tend to think of knowledge as a positive epistemic status exhibited exclusively by propositional attitudes which have as their content a representational item, like a proposition or truth-evaluable sentence. Acquaintance may be accompanied by propositional attitudes (e.g., the belief that a sensed quality exists or the belief that one is having a sensory experience), but it is not in virtue of any propositional or truth-evaluable content that acquaintance counts as knowledge. ${ }^{3}$ Neither is acquaintance's status as knowledge grounded in any dispositions to act, infer, or have other thoughts. The constitutive relation of acquaintance is what grounds the mental

\footnotetext{
1 See e.g., Russell (1911), Fumerton (1995), Johnston (2004), Gertler (2012), Chalmers (2018), and Brewer (2019).

2 I find it natural to speak of mental states with sensory phenomenology in relational terms, but my arguments for acquaintance being knowledge can be recast to be consistent with pure representationalism. One of the key claims of the paper is that it is not in virtue of any representational content that this type of mental state counts as knowledge. The relational view can explain what grounds the state's status as knowledge if not representational content, in terms of the relation of being acquainted with an object. The representationalist who denies the relational character of perception needs an alternative account of the grounds.

3 The sensible qualities may be represented as being some way in ordinary perceptual experience, as pervading the surfaces of external objects (like tables and chairs) in the case of the colors. But such representations and the associated beliefs are beside the point. It is the relation of acquaintance that grounds the mental state's status as knowledge, not any representational attitudes which may or may not accompany acquaintance.
} 
state's positive epistemic status, not the fact (if it is one) that the quality disclosed is represented as being some way, nor facts concerning the agent's dispositions. ${ }^{4}$

Closely related theses have been defended elsewhere, and despite subtle differences in the way I construe acquaintance and the stakes of the debate, the discussion is very much intended to build on previous work (Duncan, 2020; Johnston, 2011; Russell, 1911; Tye, 2009). ${ }^{5}$ For instance, several theorists find in ordinary language evidence for a distinctive species of 'object' knowledge. The verb 'to know' takes that-clauses ("I know that it is raining outside") as well as noun-phrases ("I know Susan/Barcelona/grief"). The noun-phrase construction in English and other natural languages offers some albeit superficial evidence that agents can stand in the knowing relation directly to things in a way structurally analogous to the acquaintance relation. The linguistic evidence is of limited present relevance, however, given that our talk of knowing things tracks a variety of different ways of being related to persons, places, and objects (Farkas, 2019). These are not the precise relation picked out by my present stipulative use of 'acquaintance.'

A second reason linguistic considerations are of limited present relevance is that the substantive issue of interest, ultimately, is not so much how we use the term 'knowledge,' but the evaluative significance of knowledge. As Kvanvig (2003, p. 232) writes, the "value assumption" is a central feature of our concept of knowledge: knowledge is worth valuing for its own sake. The paper's central claim is that acquaintance exhibits final (that is, non-instrumental) epistemic value, the kind of value exhibited by justified true beliefs and accessible to agents motivated to understand and know the world. I discuss what makes this species of final value, this way of being good for agents, distinctively epistemic rather than prudential or moral. ${ }^{6}$ For now, the point is just that acquaintance counts as knowledge in at least the sense that it exhibits the final value of knowledge. ${ }^{7}$

Taking its meaning to be understood, I offer several new arguments for $A \Rightarrow K$. The first three point to the principle's explanatory power: it best explains the intuitive

\footnotetext{
${ }^{4}$ There is a subtle question of the precise relation of ground at issue. The minimal claim I need to defend for present purposes is that acquaintances' final epistemic value (its value as knowledge) isn't normatively grounded in propositional or dispositional states. To put it differently, it is the acquaintance itself that is finally valuable from the epistemic point of view. In Sect. 6, I discuss the nature of epistemic value more generally and suggest that propositional attitudes and basic acts of attentional focus may be enabling conditions for acquaintance's positive epistemic status, which is compatible with my core claims.

5 Johnston (2011) characterizes acquaintance as an epistemic virtue. As I discuss below, the relevant evaluative concept is not that of a virtue but that of final (i.e., non-instrumental) epistemic valuevalue of knowledge. Duncan (2020) does not put things in terms of epistemic value, final or otherwise, but endorses the Russellian thesis that there is knowledge of things, distinguishable from propositional knowledge. One of my arguments for $A \Rightarrow K$ is structurally similar to an argument offered by Duncan in that both appeal to the functional role of knowledge. However, our reasons for thinking acquaintance satisfies the knowledge-role are distinct. See Sect. 4.

6 In the opening lines of the Metaphysics, Aristotle notes "the delight we take in our senses; for even apart from their usefulness they are loved for themselves" (1.1 980a22-28). The relevant species of love is epistemic. I discuss the nature of the epistemic good in Sect. 6 but assume that our pre-theoretic grasp on it provides a good enough basis for theorizing.

${ }^{7}$ Iaquinto and Spolaore (2019) offer a logic of acquaintance knowledge claims largely compatible with the view outlined here. Iaquinto and Spolaore assume that acquaintance knowledge of an object entails knowledge of some truth about the object (e.g., that it exists). On my view, it couldn't be knowledge of truths that explains why acquaintance is knowledge.
} 
epistemic appeal of 'Edenic' counterfactuals involving unmediated contact with reality (Sect. 2), the elusiveness of knowledge gained through acquaintance (Sect. 3), and the knowledge-like functional role of acquaintance in the context of reasoning about the good and the right, where the non-propositional objects of acquaintance serve as evidence and inferential basis (Sect. 4). A fourth argument appeals to the principle's theoretical usefulness: that acquaintance is knowledge helps vindicate claims about the relationship between knowledge and concern for others we already find intuitive or outright accept (Sect. 5). These arguments needn't be considered in isolation. While the acquaintance knowledge hypothesis may run counter to conventional wisdom in contemporary epistemology, ${ }^{8}$ there is an emerging case for it in recent literature that is broadly compatible with the view I defend here. My aim is to show that the considerations that reveal acquaintance to be a unique and undemanding form of knowledge are broad-ranging, with significant implications for normative domains beyond the epistemic.

After developing the positive case, I respond to what I take to be the two strongest objections to acquaintance being knowledge (Sect. 6) — namely, (a) that there are no pre-propositional, pre-conceptual cases of perceptual experience that remain epistemically relevant (McDowell, 2008; Sellars, 1968); and (b) that the category of knowledge appears gerrymandered once we add 'object' knowledge to the epistemological mix (Farkas, 2019).

\section{Eden's epistemic appeal}

The initial argument for $A \Rightarrow K$ appeals to an explanatory puzzle arising out of a scenario imagined by Chalmers (2006, p. 49):

In the Garden of Eden, we had unmediated contact with the world. We were directly acquainted with objects in the world and with their properties. Objects were simply presented to us without causal mediation, and properties were revealed to us in their true intrinsic glory. When an apple in Eden looked red to us, the apple was gloriously, perfectly, and primitively red. There was no need for a long causal chain from the microphysics of the surface through air and brain to a contingently connected visual experience. Rather, the perfect redness of the apple was simply revealed to us. The qualitative redness in our experience derived entirely from the presentation of perfect redness in the world.

\footnotetext{
8 The view that all knowledge is propositional (except, maybe, know-how) is more often taken for granted than explicitly defended. Williamson (2000) argues that what is known is evidence and that evidence is always propositional in nature, thus ruling out non-propositional knowledge/evidence (see Sect. 4), and perhaps the most famous objection to non-propositional experiential states having intrinsic epistemic import is due to Sellars (1968) (see Sect. 6). The assumption that knowledge must be propositional is likely implicit in the conventional wisdom that 'knowledge entails belief,' in efforts to reduce acquaintance knowledge to knowledge-that (see e.g., Hintikka 1991, pp. 212-233), and in the general analytic and argumentative focus on propositional knowledge across areas of philosophy. The treatment of knowledge of truths as the central case worth analyzing causes viable positions in, for example, the philosophy of mind and ethics to be overlooked. In what follows, I clarify some of the reasons why acquaintance knowledge warrants greater philosophical attention by highlighting the explanatory work it can do for us and its general theoretical usefulness.
} 
Eden is supposed to be perceptually indistinguishable from our world but contrasts with our world in some significant ways. On Earth, there is a "need for a long causal chain from the microphysics of the surface through air and brain" for there to be color experiences. A complex series of events involving the surface reflectance properties of the apple, photons, and chemical transformations in our retinas and brain results in the appearance as of a three-dimensional object across whose surface pervades redness. There is no such 'hidden' microphysical structure to an Edenic reality which consists entirely of objects and properties that are directly perceived, such as the apple and its redness.

Chalmers introduces Eden as a kind of epistemic ideal-its paradisaical designation is no accident-before going on to explain why it might function as such an ideal. Eden's epistemic appeal does seem intuitive. It is very tempting to think that we would have been epistemically better off in some respects had our world been Edenic. And the point of using Chalmers' thought experiment as a starting point for discussion is that the intuition that our Edenic counterparts enjoy some epistemic advantage over us seems independently and pre-theoretically accessible, even if the basis for Eden's appeal may not be entirely obvious and invites further examination.

Chalmers' discussion of Eden's relationship to visual perception suggests a possible explanation. Chalmers observes that "visual perception represents our world as an Edenic world" (p. 50). ${ }^{9}$ In other words, perceptual experience makes it seem as if the world were really populated with simple objects colored exactly as they appear without causal mediation. And so visual perception turns out to be misleading in our world. On Earth, we're told, colors do not simply pervade the surfaces of objects that are somehow immediately present in conscious awareness. Scientific investigation into the structure of our world reveals that the instinctive beliefs we form pre-scientifically on the basis of visual experience are neither true nor justified. But such beliefs would have been true and plausibly justified had we lived in the Garden of Eden. This is what explains Eden's intuitive epistemic appeal.

While plausible, the explanation seems to me to mischaracterize Eden's appeal. It is vulnerable to at least two objections. First, it is not obvious that visual experience really does present objects as instantiating color so directly that there couldn't be a mediating causal structure involving microscopic objects and properties. My visual experience when I see a red apple - the phenomenal content or what it is like-seems unaffected by whether I accept the existence of a constitutive causal structure. It's true that the possibility of such structure does not immediately suggest itself on the basis of visual experience. But that's a far cry from saying that visual experience denies it. To put it another way, the content of perceptual experience does not include a proposition of the form $<$ this is all there is $>$.

One might reply that even if perceptual content is strictly consistent with a nonEdenic world, it might, nevertheless, abductively favor Eden over Earth, perhaps

\footnotetext{
${ }^{9}$ Chalmers notes that "at some level, perception represents our world as an Edenic world, populated by perfect colors and shapes, with objects and properties that are revealed to us directly." Later, he observes the "abductive argument" from "the existence of illusions and of scientific structure to the nonexistence of perfect colors in our world" (p. 77). So, the story is very much one of deception: it seems to us that 'perfect' colors exist that are instantiated directly by objects, but they don't. Objects in the actual world may be red in some more indirect way, just not edenically red.
} 
because the simplest or most parsimonious explanation of what we perceive (prescientifically) is that the world is Edenic. ${ }^{10}$ The problem with this reply is that the simplest explanation is not always the best explanation. Indeed, there are reasons for doubting that perceptual content taken at face value abductively favors an Edenic world - that is, a world lacking in any underlying structure, where colors have no constitutive nature beyond being directly instantiated by mind-independent external objects that are likewise without constitutive structure. Our Edenic counterparts might reasonably reject such a disunified view of their world that's devoid of explanatory depth, and instead privilege various alternative hypotheses in an effort to make sense of the well-organized world they perceive-e.g., a view that posits hidden entities (gods, spirits, monads, purposive essences, an unknown something) responsible for the patterned distribution of sensible qualities and the ordered nature of sensible change; or the view that perceivers make some contribution to the character of sensory experience given the apparent privateness of sensations like pain. ${ }^{11}$ In other words, rather than favoring the stark and disunified truth about Eden, perceptual content might be uniquely misleading in Eden. ${ }^{12}$ Hence, the claim that perceptual content's evidential import confers an inferential advantage on our Edenic counterparts seems sufficiently uncertain to warrant a search for a better explanation, one that more straightforwardly captures Eden's intuitive epistemic appeal.

A second problem with the explanation is that in charactering us as deceived it relies on contestable assumptions about the metaphysics of our world. It is hardly obvious that taking seriously the facts of vision science, including its ontology of photons, surface reflectance properties, and complex neuronal events, entails denying the existence of a manifest realm of fully real and metaphysically independent macroscopic objects like tables and chairs with colors pervading their surfaces just as it appears in vision, a realm which relates in some way to the physical without being reducible to it. We might have good reasons for opposing such a view, perhaps for being undermotivated or metaphysically extravagant. But a macro-colored scenario is at a minimum conceivable. ${ }^{13}$ In fact, it is similar to Eden, although not identical. And the intuition that our Edenic counterparts enjoy an advantage over us along some dimension of

\footnotetext{
10 Thanks to an anonymous reviewer for raising the objection, who helpfully points out that the dialectic here is similar to Skow's $(2011, \S 3)$ discussion of whether experience favors the A-theory of time: "Even if it is true that each of the theories [of time] is consistent with my experience being as it is, it does not follow that the fact that my experience is that way fails to favor one of the theories over the other. This is an instance of a general epistemological truth: a body of evidence can support some hypothesis without entailing that hypothesis."

11 For a related set of criticisms of the view that naïve realism fits the 'intuitive' or pre-theoretical conception of perception, see Raineri (2021). Both sense datum theorists and naïve realists have appealed to what the content of perception is introspectively like to defend their respective views.

12 To be sure, our Edenic counterparts might get some things right-e.g., that colors are 'located' on the surfaces of objects. As I discuss below, there is reason to think we might get the locational facts right here on Earth as well. But the point of this first objection is that even if our Edenic counterparts glom on to some truths about their world better than us based on perception, they may be generally misled by the senses in ways that we aren't.

13 Chalmers acknowledges that the argument for Edenic redness not being directly instantiated by external objects in the actual world "was not a deductive argument. Rather, it was a sort of abductive argument" (p. 77). In other words, it is at least conceivable that Edenic redness is instantiated in our world. Brewer (2019), for example, denies that the scientific facts highlighted by Chalmers count against the 'naïve' view
} 
epistemic evaluation withstands the assumption, it seems to me, that our world is a macro-colored world.

We need an explanation for Eden's appeal that avoids contestable assumptions about the content of visual experience and the metaphysics of macroscopic objects in our world. ${ }^{14}$ Here is one: Eden is 'edenic' because it represents a world that is more fully knowable by acquaintance than ours. In fact, everything that exists in Eden-namely, the entities available to perception — can be directly perceived. The world reveals itself and the intrinsic nature of the things which populate it, leaving nothing hidden from acquaintance. Our world, by contrast, is densely populated with 'invisibilia' - the electrons, protons, and fields — which are known only indirectly, through their effects on other things, and by the ways in which they help us understand and predict the behavior of the mosaic of sensible qualities. We do not (and, as far as one can tell, cannot) perceive the intrinsic nature of a proton in the way that we do the intrinsic nature of scarlet. Eden is epistemically appealing in this specific respect: it represents a world that can be known by direct acquaintance to a fuller extent than our world.

This is not to say that the objects and properties we know indirectly in our world aren't known in valuable ways. Our inferential knowledge of microphysical truths is certainly worth valuing epistemically. The explanation relies solely on the assumption that acquaintance is one way to have knowledge of objects, indeed, a uniquely attractive way, and that it would be epistemically better if we could also know through acquaintance the objects we know in our world only by means of inferring truths about them. So, a reason to accept that acquaintance is knowledge is that it helps us explain why Eden presents as a kind of epistemic ideal. Our Edenic counterparts are closer to the ideal of having complete acquaintance knowledge of one's world than we are.

However, an alternative explanation of the facts might seem tempting-namely, that there is propositional knowledge to be had about objects for which acquaintance is necessary. Since we shall revisit this alternative proposal several times over the course of the paper, it would be good to give it a name:

Propositionalism There is some propositional knowledge to be had about entities (e.g., <This is what redness is like $>$ ) that requires being acquainted with the entities in question

The propositionalist alternative amounts to a weaker explanation of Eden's appeal. What needs to be explained is the fact that our Edenic counterparts do better along

Footnote 13 continued

of how objects are colored in our world. My point here is that Eden seems preferable even if we assume that Edenic redness is directly instantiated in our world.

14 Put differently, Chalmers' account of why Eden functions as an epistemic ideal relies on two controversial claims: that perception is more likely to lead our Edenic counterparts to the truth about their world and that perception is more likely to lead us to falsehoods. Neither seems true, or at least we have reason to doubt both claims - the first because perception does not necessarily favor the truth about Eden, and the second because our world could be 'Eden+' (primitive colors + hidden structure). Even if we were to accept that perceptual content abductively favors Eden over Earth, it seems unlikely that this would be the only epistemic advantage of living in an Edenic world. The abductive argument focuses on inferential knowledge that is achievable in Eden. However, some subjects are unreflective and do not draw many conclusions about the nature of their reality. They might still be epistemically better off than their Earthly counterparts, precisely because in Eden, they enjoy a direct acquaintance relation with the structure of the world. We can fully explain the epistemic advantages offered by Eden only if we think of acquaintance as a kind of knowledge. Thanks to Carlotta Pavese for suggesting that I make this point explicit. 
some epistemic evaluative dimension than we do. And it is just not obvious that our counterparts do better in terms of believing propositions true at one's world or having justified true beliefs. We certainly do worse than we would in Eden insofar as we do not know some acquaintance-dependent truths about our world: those concerning electrons, protons, and fields. But we do better insofar as we know a great many truths about such entities, whereas our counterparts in Eden only know truths about the sensible qualities. In other words, the fact that we do not and cannot know certain truths about our world is counterbalanced by the fact that there are more truths to be known. So, in terms of knowing truths at a world, our counterparts in Eden are not so obviously better off.

By contrast, if acquaintance exhibits the final value of knowledge, albeit a determinate form of that value distinct from propositional knowledge, we can straightforwardly explain Eden's preferability along a clear and distinct epistemic evaluative dimension. We lack acquaintance knowledge of many objects and properties in our world, whereas our counterparts do not lack the relevant species of knowledge of objects and properties in their world. Furthermore, our lack of acquaintance knowledge is not compensated by our being acquainted with more objects than our Edenic counterparts, since Eden is supposed to be sensibly identical with our world. And since there is no reason to suppose that acquaintance knowledge is straightforwardly commensurable with propositional knowledge, Eden is clearly preferable along a dimension of final epistemic value: the good of acquaintance. ${ }^{15}$

So, $A \Rightarrow K$ offers a better explanation of Eden's epistemic appeal than the propositionalist alternative. ${ }^{16}$ If the explanatory edge seems small for purposes of identifying the best explanation, we can draw a disjunctive conclusion: either acquaintance is knowledge or else there are some truths about objects that can only be known through acquaintance. The propositionalist alternative will be shown to be a consistently weaker explanation of relevant explananda in subsequent arguments, which together should shift the overall weight of the evidence more decisively in favor of $A \Rightarrow K$.

\footnotetext{
15 It might help to compare distinct species of the prudential good. Pleasure, friendship, and personal achievement are all prudentially good. But as determinate forms of the prudential good, they aren't perfectly commensurable, as evidenced by the fact that having fewer friends is not straightforwardly compensated by an increase in experienced pleasure. Something similar holds, I contend, in the case of non-instrumental epistemic value: it is an evaluative determinable with imperfectly commensurable determinants. I discuss these points further in Sect. 6.

16 In personal correspondence, Chalmers agrees with my construal of Eden and that it is epistemically appealing in the way I describe, but questions whether we should necessarily use the label 'knowledge' to describe the final epistemic value of acquaintance. As discussed earlier, the verbal question (while not irrelevant) is of limited interest. The substantive point is that acquaintance exhibits final epistemic value. I'm satisfied with calling it 'knowledge' because one of the central ways we ordinarily use the term is as a marker of this species of final value (Kvanvig 2003). In any event, the arguments to follow show that acquaintance satisfies the conceptual role of knowledge in other ways as well.
} 


\section{Elusive knowledge gained through acquaintance}

$A \Rightarrow K$ is explanatorily useful in other contexts: it clarifies the precise upshot of Jackson's (1982) famous 'knowledge argument.' Jackson's original setup hardly needs rehearsing. Mary locked inside her black and white room acquires knowledge of all the physical facts concerning color experience, including the way light is reflected by surfaces and the changes in the retina and visual cortex which result in color experience. When Mary steps out of her room and sees a red object for the first time, it seems undeniable that she learns something new, which in turn suggests that the knowledge she gains is not reducible to the truths she knew about physical objects and properties prior to her perceptual experience.

Several writers suggest that what Mary gains is new acquaintance knowledge that is "logically independent of our knowledge of truths" (Conee, 1994; Tye, 2009, pp. 131-133). ${ }^{17}$ These proponents of the acquaintance knowledge hypothesis as a solution to Jackson's puzzle defend it on the grounds that it is consistent with both the powerful intuition that Mary learns something new and the conviction that the standard physicalist account of worldly facts needs no supplementation based on ordinary perceptual experience. ${ }^{18}$ The existence of the relevant nonfactual species of knowledge is largely taken for granted by these theorists as finding support in ordinary language, though, as I indicated earlier, the evidential upshot of ordinary language seems mixed at best (cf. Crane, 2012; Farkas, 2019). ${ }^{19}$

There is a different way of defending the acquaintance knowledge hypothesis as an account of what Mary gains. It involves appealing to an underdiscussed feature of Mary's situation that alternative accounts have a hard time explaining - namely, that Mary is unlikely to retain all of the new knowledge she gained once she returns to her black and white room. Tye (2009: p. 98) speculates in passing that Mary "may not know that shade of red a few moments later after turning away," but does not take it to be an independently motivated feature of the case. Far from being a mere upshot of the acquaintance knowledge hypothesis, the elusiveness of the knowledge Mary gains is, I argue, an intuitive feature of the case that invites explanation. It is best explained by our hypothesis. ${ }^{20}$

\footnotetext{
17 Others appeal to acquaintance as a way of resisting the knowledge argument: Mary becomes acquainted with red, but she does not gain new knowledge (Balog 2012). The discussion is primarily directed at those who concede that new knowledge is gained.

18 I doubt this is the best way to motivate the hypothesis because it is tempting to think that May gains both acquaintance knowledge and acquaintance-dependent knowledge of truths that aren't captured by the physicalist.
}

19 Tye's $(2009$, pp. 95, 98-99, 131) defense of acquaintance knowledge is primarily based on ordinary language ("I may not know any truths about that shade of red; but as I view the shade, know it I do in some ordinary basic sense of the term 'know'.") Crane (2012) argues that Tye is not entitled to appeal to the ordinary notion of knowing to establish that there is acquaintance knowledge in the sense presently at issue. See also Farkas (2019).

${ }^{20}$ Elsewhere, Tye (2000) observes "For you won't remember it accurately, when you take your eyes from the rose.... Perhaps it is correct to say that Mary never really learns what it is like to see red17. For learning arguably requires not just knowledge but the retention of that knowledge." Tye's reliance on Russell's distinctive account of acquaintance is in fact in tension with the elusiveness of the knowledge Mary gains. Russell thinks (for reasons that needn't detain us) "I am acquainted with an object even at moments when it 
In her colorless room, post-acquaintance, Mary retains many of the new beliefs, dispositions, and linguistic abilities she acquired through her acquaintance with redness. For example, she believes that moments ago she had an experience unlike any prior experience. When she encounters another instance of redness in the future, she will be disposed to recognize it as red. She might have gained the ability to remember or imagine red as a result of her acquaintance (Lewis, 1990). Additionally, Mary retains the new vocabulary she might have acquired through her experience. E.g., she has a name which picks out the particular shade of red she saw ("phenomenal red33").

Yet none of these retained beliefs, dispositions, and linguistic competences seem to perfectly capture the knowledge Mary gained through her vivid encounter with redness, suggesting that not all of the new knowledge is preserved. For one, Mary conceivably could have acquired similar beliefs and dispositions (or introspectively indistinguishable ones) without first experiencing redness. Consider the disposition to recognize the color red. Evidence of subjects with blindsight acquiring information from their visual systems without conscious awareness, including wavelength information, supports the view that Mary conceivably could have acquired color recognition capacities independently of a phenomenally conscious experience of redness (Brogaard, 2011; Raymont, 1999). This suggests that the disposition to recognize red does not capture the knowledge Mary gains from her phenomenally rich experience. ${ }^{21}$ Likewise, Mary might have had a name all along for phenomenal red33, for she might have assumed the existence of unseen qualities before ever encountering colored objects. As for the ability to imagine or remember, there is nothing in Jackson's description of the case which excludes the possibility of Mary possessing the (unexercised) ability to spontaneously experience or hallucinate redness in her black and white room, an ability which would be hard to distinguish from the ability to imagine or remember redness.

As for remembrance itself, as opposed to the ability to remember, ordinary cases of remembering redness lack the phenomenal vividness and depth of seeing redness, which seems to be evidence of an epistemic contrast (a point I return to below): one does not know redness fully when one merely remembers a prior experience. However, if it turns out that certain powerful forms of remembrance are experientially indistinguishable from seeing, then Mary may have full knowledge of redness when she remembers her prior acquaintance but only because she seems reacquainted with redness through such remembrance. Our present use of 'acquaintance' is neutral between a hallucinatory experience as of a red dagger and seeing a red dagger. We are equally acquainted with redness in the two cases. So, the appeal to phenomenally

\footnotetext{
Footnote 20 continued

is not actually before my mind, provided it has been before my mind, and will be again whenever occasion arises" (Russell 1910, p. 109). But the knowledge Mary gains is partly lost when she looks away, as I argue below. The technical notion of acquaintance knowledge presently at issue is one on which the knowledge is constitutively tied to a present acquaintance.

21 It's true that the disposition to recognize red based on information acquired through blindsight is not identical to a disposition to recognize red based on its qualitative character. But it would be hard to tell the two dispositions apart in awareness. How does Mary know when she has a phenomenally conscious experience of red that she doesn't recognize the color based on a mechanism like blindsight that bypasses the phenomenology? And since it is tempting to suppose that Mary has introspective access to the fact that she gains new knowledge the first time she has a phenomenally vivid experience of redness, the knowledge she gains should be introspectively distinguishable from a capacity she could have acquired from a phenomenally blind encounter with red.
} 
indistinguishable remembrance or visualization would prove the point that knowing redness fully requires being acquainted.

It might be objected that our ordinary knowledge attributions seem to support the opposite view: so long as Mary has the ability to perfectly visualize redness at will, she knows the color even when she isn't exercising the ability. ${ }^{22}$ However, we also find it natural to say that Mary in her black and white room knew the color red before seeing it because of her detailed knowledge of the physical facts about colors. Such attributions do not settle the question of whether Mary knows fully. The present claim is not that she loses all of the knowledge she gained from seeing red when she isn't visualizing, but that she loses some of it.

We can motivate this claim further by imagining that Mary retains her ability to visualize redness perfectly but does not exercise the ability for a long time-say, a period of many years. Suppose that her ability to visualize redness does not weaken and that she knows of its enduring strength (perhaps she receives assurance from an oracle). Still, when she does finally visualize the color, it would be quite natural for her to feel that she had forgotten the shade. Her occurrent visualization is likely accompanied by a sense of rediscovery. But if there is something she forgets of redness after a period of years of not exercising her full-strength ability to visualize, the same should be true after a few seconds of not exercising the ability, given that the mere passage of time between visualizations should not make an intrinsic epistemic difference. Knowledge can fade over time due to changes in our abilities, but Mary retains hers at full strength. While Mary may not experience the same sense of rediscovery after a few seconds of not visualizing, the point is that upon reflection she should realize that the epistemic significance of not visualizing remains the same, whether a few seconds or a few years have passed. The difference between the cases is that Mary is more likely to attend to the loss of knowledge when she can contrast a longer stretch without seeing redness with the distinctive knowledge gained from visual experience. Reflection on such cases suggests that the mere ability to visualize redness perfectly is insufficient for fully preserving the kind of rich knowledge Mary has of redness when she visualizes, even if she can easily recover the lost knowledge by exercising her abilities.

There is another way of motivating our crucial observation:

Elusiveness There is some knowledge that Mary gains whose persistence seems to require a persisting state of acquaintance

The intuition that Mary learns something new is based on a sharp phenomenal contrast between Mary's mental states prior to seeing red and her mental states during acquaintance. Mary's world lights up in an entirely novel way when she sees a red object for the first time. This phenomenal contrast is our primary evidence of an epistemic contrast. But Mary's state of being acquainted with redness stands in a similar (even if not as stark) contrast with her post-acquaintance mental states, given that the nature of redness was especially vivid and transparent to Mary during acquaintance. This enduring phenomenal contrast is equally good evidence of an epistemic contrast between Mary's acquaintance and the sum of her new beliefs and dispositions in her colorless room post-exposure. Epistemic contrasts are not always due to differences in

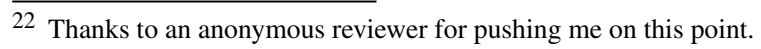


knowledge. Differences in the degree of evidential support or justification for Mary's beliefs during and after acquaintance might account for the contrast, and we'll consider shortly the viability of explaining the contrast in justificatory terms.

Anyone who accepts that Mary gains new yet somewhat elusive knowledge needs to explain its character. A good explanation for ELUSIVENESS is that acquaintance just is knowledge. If the knowledge Mary gains were reducible to, say, propositional knowledge, it would be mysterious why her knowledge is elusive in this way, given that propositional knowledge, e.g., the knowledge that Fido is a dog, does not generally depend on acquaintance for its persistence. While propositional knowledge can certainly fade over time, its fading is usually explained in terms of a loss of belief or justification, or the weakening of dispositions which once grounded one's beliefs, e.g., the disposition to assert the proposition. Likewise, 'know-how,' consisting of an agent's practical dispositions, does not require for its persistence acquaintance with sensible qualities. 'Know-how' persists so long as the relevant dispositions do, and there is no reason to suppose that the practical dispositions Mary gains from acquaintance with redness should immediately weaken post-acquaintance. Accordingly, $A \Rightarrow K$ does important explanatory work.

To show that $A \Rightarrow K$ is explanatorily indispensable, we need to rule out an alternative explanation in justificatory terms:

Propositionalism about Mary's elusive knowledge What Mary loses upon her return to her black and white room is justification for a unique propositional attitude she acquired through acquaintance

Grzankowski and Tye (2019) suggest that Mary acquires a new belief which has as its content a demonstrative proposition, such as $<$ this is what redness is like $>$ or $<$ this is red $>$ where "this" picks out the quality Mary is acquainted with (cf. Howell, 2013, ch. 6). A present state of acquaintance may be necessary for such beliefs to be justified. On the resulting proposal, the knowledge Mary gains is propositional in nature, a demonstrative answer to the question "what is redness like?", but the knowledge is elusive: the belief is only justified so long as one is presently acquainted. ${ }^{23}$

If the explanation is to work, the demonstrative belief (or whatever belief it is whose justification turns on whether Mary is presently acquainted or not) better not itself be a state of acquaintance with redness. The belief, we're imagining, counts as an instance of knowledge not in virtue of being acquaintance, but rather in virtue of being justified by an independent state of acquaintance. If what it is to believe this is the nature of redness is to be acquainted with redness, then acquaintance plays an essential role in constituting knowledge, and having admitted this much, it is unclear why we shouldn't just take acquaintance to be knowledge. ${ }^{24}$ So, the propositionalist needs the acquaintance and belief to be essentially distinct.

\footnotetext{
23 Note that any account of the epistemic contrast between Mary's mental states during and after acquaintance in justificatory terms needs to identify the relevant belief whose justification turns on present acquaintance. 
But if the acquaintance forms no part of what it is to have the demonstrative belief, then it is implausible that the belief could capture what Mary knows ever so elusively when she becomes acquainted with redness. Suppose Mary undergoes a procedure which causes her mental life to be split in two as soon as she forms the demonstrative belief. Her left brain believes this is what redness is like, has the meta-belief that her belief is based on an acquaintance experienced by her right brain and that "this" picks out the object of acquaintance, but does not experience a mental state with reddish phenomenal character. Lefty Mary is no longer acquainted with red whereas Righty Mary continues to be. The former would surely experience her new situation as epistemically diminished (on the basis of the experienced phenomenal contrast), and the epistemic loss cannot be explained by her lacking justification for her demonstrative belief, because, by stipulation, the belief is justified by virtue of being caused in the right sort of way by a presently occurring acquaintance (Righty Mary's). ${ }^{25}$ The procedure we're imagining Mary undergoes does not sever the causal or otherwise justificatory connection between the two mental states. It simply blocks Mary's access to the phenomenal content of experiences attributable to part of her brain. The propositionalist cannot explain the diminution in Lefty Mary's epistemic situation, a puzzle we avoid by assuming acquaintance itself is knowledge.

In short, knowledge acquired through acquaintance exhibits a feature that invites explanation: it depends for its full preservation on the acquaintance persisting. Standard accounts of the knowledge Mary gains have a hard time explaining this feature. By contrast, the acquaintance knowledge hypothesis straightforwardly explains it, which is a good reason for accepting the hypothesis.

\section{The knowledge-role in evaluative reasoning}

A third argument for $A \Rightarrow K$ appeals to the functional role of knowledge (cf. Duncan, 2020). ${ }^{26}$ What one knows is generally good evidence for one's beliefs (cf. Williamson, 2000). ${ }^{27}$ If I know, based on Sarah's testimony, that Sam committed a hit-and-run, what I know is excellent evidence for my belief that Sam committed a felony. We regularly reason from what we know. I can reason from my testimonial knowledge that Sam committed a hit-and-run to Sam drives a car. If I fail to report the hit and

\section{Footnote 24 continued}

This is true even if acquaintance with redness forms a mere part of the demonstrative mental state. In characterizing what knowledge is, we would be helping ourselves to the state of being acquainted. Acquaintance would thus be playing a role in constituting knowledge and exhibiting the value of knowledge, which is a result I am happy with for present purposes.

25 The point stands regardless of how the propositionalist solves Davidson's puzzle of saying how it is that experiential states justify beliefs formed on their basis, so long as the acquaintance is held to be constitutively independent of the belief. See discussion in Byrne (2016).

26 Duncan (2020) invokes knowledge's functional role in arguing along similar lines that perceptual experience is knowledge. Duncan suggests that perceptual experience serves as evidence and inferential basis for our beliefs about the external world. But there is an even stronger argument to be made for perception satisfying knowledge's functional role in the case of evaluative reasoning, as I explain below.

27 I endorse Williamson's E(vidence) $=\mathrm{K}$ (knowledge) principle but make it more general in what follows: the evidence is different in kind depending on the kind of knowledge. 
run, my knowledge of Sam's conduct would be part of the explanation for why I am blameworthy.

The knowledge-role is paradigmatically satisfied by beliefs which have as their content propositions. It is the propositions which stand in evidential and inferential relations to one's other beliefs (Williamson, 2000, pp. 194-203). Accordingly, if there are cases of acquaintance satisfying the knowledge-role, the non-propositional objects of acquaintance should similarly serve as evidence or inferential basis for at least some of our beliefs. In other words, to produce functional evidence of acquaintance being knowledge we need examples of a belief that is justified by an object of acquaintance rather than the content of a propositional attitude.

Such examples can be found in distinctly evaluative beliefs and reasoning. Consider pain and our evaluative judgments about pain. To experience pain is to be acquainted with a sensible quality that exhibits such features as intensity, location, and duration. We can leave open whether it is a quality of the subject's bodily states (tissue damage and the like) or some type of somatic/affective field; and whether an experience of pain involves representational content, including evaluative representational content. ${ }^{28}$ The focus for now is on the quality with which we are directly acquainted, consistent with the background assumptions about states with sensory phenomenology clarified at the outset. An acquaintance with pain (henceforth, 'pain' refers specifically to the sensed quality) provides excellent evidence for the evaluative belief that pain is bad. We can reason from an acquaintance with pain that it would be good to acquire painkillers. And one can be blameworthy for causing someone else pain partly in virtue of one's acquaintance with pain. Moreover, evaluative beliefs formed during and after painacquaintance exhibit an epistemic difference. No doubt my belief in pain's badness remains well-supported when I am no longer acquainted with pain. But I had especially good evidence that pain is bad when I was in the grip of a painful acquaintance.

None of this should be ethically controversial. That natural (or non-normative) phenomena provide at least some portion of our total evidence for our evaluative conclusions is widely accepted. The claim is compatible with our evaluative judgments also being supported by irreducibly moral or evaluative evidence. ${ }^{29}$ The present challenge is to characterize precisely the evidence that is drawn from experience. I contend that the evidence is not propositional in nature. It is the pain itself, the object of acquaintance, which counts as evidence for the belief that pain is bad.

There are several reasons for doubting that a proposition-the content of a belief based on one's acquaintance with pain-could serve as evidence. First, it is hard to

\footnotetext{
28 A number of contemporary philosophers of pain are attracted to the view that pain experiences have representational content. For example, an experience of pain might represent tissue damage or some other kind of disturbance in one's body (see e.g., Tye 2006). According to 'evaluativists', the representational content of pain includes the badness of an injury or sensation. As discussed below, my argument is compatible with such views so long it isn't assumed that representational content exhausts what it is to experience pain. As clarified at the outset, the entire discussion is premised on the assumption that states with phenomenal content are best explained in relational terms, as essentially involving acquaintance with sensible qualities. Indeed, 'pure' representationalism seems to me to mischaracterize the most salient aspect of a painful experience-the affective phenomenology.

29 The argument is compatible with one's evidence including the deliverances of some unique faculty for evaluative insight. For what it is worth, I doubt the existence of such a faculty and take the evidence for our evaluative convictions to be entirely naturalistic.
} 
say what its content would be, which is significant given the contrastive obviousness of the evaluative conviction. Ordinary certainty that pain is bad does not depend on complicated inferences or subtle observations. Second, the hypothesis that it is some proposition about pain or about one's experience of pain that we take to be evidence that pain is bad and base our evaluative convictions on has little phenomenological attraction. It is the sensible content of the experience I train my thoughts on and that motivates me to act. ${ }^{30}$

Third, it is of considerable significance that we do not justify our basic evaluative convictions by adverting to facts or propositions. If pressed to state some proposition about pain (some perception-based 'knowledge that') as justification for their basic evaluative beliefs, ordinary ethical agents would be at a loss, an observation that finds support in the empirical research on "moral dumbfounding"- the inarticulateness exhibited by individuals invited to justify their basic evaluative commitments. ${ }^{31} \mathrm{By}$ contrast, we routinely invoke facts to justify our comparably basic non-evaluative beliefs, including beliefs about the external world. E.g., it would be natural for me to advert to the fact that I can see the shirt is green-a believable fact about my perceptual experience-to justify my belief that the shirt is green. Analogous justifications offered in propositional terms don't seem apt for basic evaluative beliefs. "I2 "I feel that pain is bad" or "people feel that pain is bad" would be neither persuasive nor responsive in quite the same way if one were invited to justify one's belief in the badness of pain or the wrongness of inflicting pain. In fact, utterances like "I feel that pain is bad" are more likely to be interpreted as the speaker merely 'opining'- that is, confessing to a belief she is not in a position of being able to defend-rather than as a citation of support or justification. The contrast with ordinary perceptual beliefs is striking: "I see that the shirt is green" is clearly justifying.The propositionalist owes us an explanation of this asymmetry. ${ }^{33}$

\footnotetext{
30 My observations here are compatible with causal theories of the epistemic basing relation (Moser, 1989, p. 157) as well as doxastic theories (Leite 2008). The pain I am acquainted with may be the causal sustainer of my belief that pain is bad. And there is no obvious incoherence in the meta-belief that pain is a good reason to believe that pain is bad.

31 The empirical literature focuses on cases where participants deem conduct wrong that is not obviously harmful (Haidt 2001; Hauser et al., 2007). As far as I know, there have been no reported studies exploring moral dumbfounding as it relates to relatively fundamental harm-involving evaluative convictions, like 'pain is bad' or 'it is wrong to inflict pain.' One explanation offered for the lack of reported studies is that it wouldn't be at all surprising to discover that agents struggle to articulate justifications for such basic evaluative convictions (cf. Nichols 2004, p. 20, fn. 9).

32 Propositional explanations are of course viable for non-fundamental evaluative conclusions (that is, conclusions that aren't evaluatively fundamental). Note that in speaking of 'foundational knowledge' I do not mean knowledge that is not obtained from any inferential process whatsoever.

33 The fact that perceptual evidence does not logically entail that pain is bad does not explain the asymmetry. Perceptual evidence does not logically entail that the shirt is green either. The propositionalist could respond by denying that our evaluative judgments are truth-apt or evidentially well-supported, but the view would be hard to maintain. The generally accepted position in contemporary ethics as well as more broadly is that at least some of our basic evaluative beliefs are justified. Evaluative beliefs may be different in various ways from non-evaluative beliefs (e.g., evaluative beliefs typically involve motivation), but it is not clear why such differences should bear on the argument. The burden is thus squarely on the propositionalist to explain why we should disregard the structure of evaluative judgments in thinking about knowledge and justification.
} 
Dumbfounding - our difficulty articulating truths as justification for our basic evaluative beliefs which intuitively seem to depend for their justification on naturalistic evidence drawn from perceptual experience-constitutes evidence that acquaintance satisfies the knowledge-role directly in such cases. ${ }^{34}$ It is tempting to think both that (1) we have evidence for the belief that pain is bad based on experience and (2) that the evidence is inexpressible, which suggests that some inexpressible aspect of one's experience with pain provides evidential support. The pain quality with which one is acquainted is just such a feature. Objects of acquaintance are not expressible in the way that propositions are (they may not be expressible at all), and acquaintance knowledge (being object knowledge) does not have the right structure to derive from it a truth in propositional form.

The argument is helpfully contrasted with one put forward by Duncan (2020). Duncan suggests that perceptual experience plays the knowledge-role in relation to beliefs about the external world. E.g., one's perception that the shirt is green delivers excellent evidence for one's belief that the shirt is green (p. 13). As noted above, we need some reason for thinking it is the objects of perception which serve as evidence for the belief rather than a proposition believed about one's perceptual experience, especially since there is an argument to be made that perception essentially involves propositional content and belief (cf. Byrne, 2009; Glüer, 2009). Duncan does not provide such a reason, and we cannot appeal to dumbfounding in such cases. ${ }^{35}$ We routinely justify our beliefs about the external world in propositional terms. While the fact adverted-to concerns one's experience ("I see that the shirt is green"), it is nevertheless a believable fact cited as evidence, which is more grist for the propositionalist mill. Likewise, even simpler non-evaluative beliefs like 'the pain is in my shoulder' or 'the pain is mild' are usually and successfully explained in propositional terms. If a physician asks me how I know that the pain is in my shoulder (or how I know that the pain is mild), it would be entirely natural for me to respond with "I can feel it in my shoulder" (or "I can feel that it's mild”). In ordinary contexts, such responses are recognized as straightforwardly justifying.

How people verbally justify their beliefs needn't be taken as decisive evidence for the actual justificatory structure. There may be some explanation for why we advert to facts as justification in the simple perceptual case, one that's compatible with the claim that perceptual acquaintance provides non-propositional justification. However, it is a stronger dialectical position to be in to be able to point to some feature of our verbalized reasoning that positively supports the claim that acquaintance is knowledge rather than merely being possibly consistent with it. Propositional content should be expressible, but expressible evidence is not what we find in the evaluative case. My evidence for taking pain to be bad is not the fact that I am acquainted with pain or some other expressible fact about pain, like the fact, if it is one, that when I experience pain

\footnotetext{
34 It's true that justifications needn't always be easily accessible. But the ordinary seeming is that we do have some accessible naturalistic justification for thinking pain is bad. Moreover, the difficulty articulating justifications for basic evaluative beliefs persists despite reflection.

35 In personal correspondence, Duncan offers as a reason that it seems intuitive that we have evidence based on perceptual experience in the non-evaluative case even when we don't form any beliefs about our experience. But there are reasons for thinking that perception essentially involves propositional content (see Sect. 6). The present argument is neutral with respect to this possibility.
} 
it seems to me that pain is bad; but the pain itself as the non-propositional object of my painful acquaintance. ${ }^{36}$ In this, my painful acquaintance is functionally knowledge: its object counts as excellent evidence for evaluative belief.

The argument relies on Williamson's (2000, pp. 200-203) 'E = K principle' (what one knows is evidence and what is evidence is known), yet its conclusion is inconsistent with Williamson's claim that evidence is always propositional in nature (pp. 194-200) (cf. Sellars, 1968). While I endorse the $\mathrm{E}=\mathrm{K}$ principle, my suggestion here is precisely that we need to generalize it for different kinds of knowledge: the kind of thing which counts as evidence varies depending on what species of knowledge we're talking about. ${ }^{37}$ The cases of object-justified belief I've highlighted seem to me to provide adequate grounds for generalizing. One might have independent reasons for doubting that non-propositional entities could ever epistemically justify. ${ }^{38}$ But independent doubts do not defeat an argument from cases.

To illustrate, one of Williamson's principal arguments for the claim that evidence is always propositional is that our formal models for belief update and revision (as well as our models for reasoning about knowledge) take for granted that we update on the basis of propositions (or entities with propositional structure) (cf. Makinson, 2003). That our best formal models represent beliefs as propositionally updated does not show that we never update based on non-propositional entities. It shows that objectbased beliefs escape the formal epistemologist's scrutiny, for which there are several plausible explanations. Few and relatively foundational beliefs are likely to be objectbased, and there might be very little of interest to say, formally, about such beliefs, but the lack of formal interest would not diminish their reality. In any event, there is burgeoning interest in acquaintance knowledge as a worthy object of formal study in its own right. ${ }^{39}$

More to the point, the absence of systematic formal study of object-based beliefs does not explain what (if anything) is wrong with the argument presented or the offered examples. It amounts at best to an independent objection to taking acquaintance to be knowledge, and a weak one for the reasons outlined. In Sect. 6, I take up independent objections more directly. The present focus is squarely on the positive case for $A \Rightarrow K$,

\footnotetext{
36 The argument does not turn on whether pain experiences involve distinctly evaluative representational content. We can grant the evaluativist's claim that when I experience pain, my experience represents the badness of an injury or sensation. Still, the question arises: what, precisely, is my evidence for my belief that pain is bad? Moral dumbfounding especially when contrasted with the explanations we provide for ordinary non-evaluative beliefs (we regularly refer to facts about how things seem to us as justification) supports the view that one's evidence in the evaluative case is not a fact about the representational character of one's experience-e.g., the fact that it feels or seems to me that pain is bad. Rather, it must be some inexpressible aspect of experience that provides rational support. A natural (and phenomenologically plausible) suggestion is that what justifies my belief in the badness of pain is the sensed quality - pain-with which I am acquainted. I suppose one could alternatively hold that the pain experience as a whole is inexpressible and non-propositionally justifies my belief, which seems close enough to the view I'm defending to leave it open as a possibility. Thanks to an anonymous reviewer for pushing me on this point.

37 Thanks to Carlotta Pavese for pushing me to make this explicit.

38 Those doubts would have to contend with the fact that rules of inference justify conclusions without being propositions on pain of regress (Carroll 1895).

39 Iaquinto and Spolaore (2019) suggest an epistemic logic which licenses inferences from acquaintance knowledge to propositional knowledge about what exists. See also 'awareness' logics based on work by Fagin and Halpern (1988).
} 
to which we are entitled to add, for all that has been said, that basic evaluative beliefs about the good and the right seem at least partly based on and justified by the sensible objects of acquaintance, showing that acquaintance satisfies knowledge's functional role.

\section{The connection between knowledge and impartial virtue}

A principle's usefulness in helping establish independently plausible claims is a reason for accepting it. For example, the fact that proofs for a wide range of accepted and mathematically interesting claims in set theory rely on the axiom of choice is one of Zermelo's main arguments for accepting the axiom (Maddy, 1988). Likewise, we have reason to accept that acquaintance is knowledge for its role in vindicating an important bit of moral commonsense.

An idea that finds recurring expression across a wide range of literary, philosophical, and religious works is that the failure to be moved by the suffering of others amounts to a distinctly epistemic failing, a kind of ignorance of worldly conditions (Marshall, 2019). ${ }^{40}$ Despite its broad appeal, the intuited connection between moral and epistemic failure is difficult to vindicate on ethically neutral grounds. Knowledge of non-moral truths does not necessarily entail other-regarding motivation. One might have broadly philosophical grounds for thinking this, but ordinary experience provides ample confirmation: agents do not necessarily acquire concern for general suffering from reading books about suffering or from all the propositional knowledge to be gained from first-hand acquaintance with suffering, as evidenced by the familiar indifference exhibited by propositionally knowledgeable agents. The uncaring may lack knowledge of 'inherently motivating' irreducibly moral truths, e.g., that one morally ought to care about the suffering of others. But inherently motivating truths are mysterious (Mackie, 1977) and invoking such truths in explanation involves giving up on an independent or non-moral explanation for the connection between epistemic and moral failure. ${ }^{41}$ These challenges lead Blackburn (1984: 22) to observe that a non-question-begging argument that could show the uncaring to be "reasoning badly or out of touch with the facts" would be the "holy grail" of moral philosophy. ${ }^{42}$

Indifference to other people's suffering can be explained as an epistemic failure, though not a failure to know the truth. On a plausible construal of what it is to suffer, we lack acquaintance knowledge of the sensible content of others' suffering. There are different forms of suffering, both emotional and physical, and there may be cases of "suffering without subjectivity"- that is, suffering in the absence of phenomenal feels (Carruthers, 2004). But a paradigmatic and morally urgent form of conscious suffering involves affective as well as motivational phenomenology. To suffer, in this

\footnotetext{
40 Marshall (2019) provides an illuminating exploration of this theme across philosophical as well as nonphilosophical sources. I discuss Marshall's own attempt at justifying ordinary moral wisdom below, which I believe comes closest to the acquaintance-based view. See fn. 47.

41 We can assume for present purposes that there are no irreducibly moral properties or facts, certainly none to be acquainted with in perception.

42 I shall not evaluate previous attempts at meeting Blackburn's challenge. Suffice it to note the arguments on offer fall well short of being widely persuasive.
} 
familiar sense, is to be acquainted with a complex of sensible qualities, including pain and felt aversions to pain $^{43}$; and whether we conceive of these qualities as exemplified by bodies, somatic/affective fields, or a subject's experience, a reasonable assumption is that we lack acquaintance with (and, correspondingly, knowledge of) the sensible content of others' suffering.

The idea that knowing fully requires experientially sharing the same sensible qualities that others experience may seem radical but is no more so than the epistemic principle on which it is based and that we're presently assuming for argument's sake. If acquaintance were merely a source of propositional knowledge, a matter simply of being familiar with some truths about what one is acquainted with (e.g., 'this is what pain feels like'), it might be enough to be acquainted with one's own pains to be fully knowledgeable about on-going pain and suffering. But acquaintance is a distinctive form of object knowledge, and we are neither acquainted with nor know in the relevant sense the sensible content of other people's suffering. ${ }^{44}$ In fact, no state we ordinarily experience could possibly serve as a perfect epistemic substitute for being directly acquainted with the qualities present in another's experience, not even believing that someone is in pain and experiencing empathy or compassion for them.

We can, however, imagine what direct acquaintance would be like. Whether the scenario is physically possible is beside the point; the ordinary moral intuition concerns what is conceivable, and there is no obvious bar to conceiving of a situation where one comes to have first-hand acquaintance with the sensible content of other people's experiences. A familiar trope of science fiction involves two subjects experiencing the same phenomenal particulars because of neural connections established between their brains. Zagzebski (2013) invites us to imagine an "omnisubjective" agent with a conscious grasp of "every conscious state of every creature from that creature's own perspective." Less ambitiously, one might imagine experiencing sensations in a different location than one is used to, or an expansion in one's overall experiential field. The accounts of patients who suffer from 'supernumerary' phantom limb pain and claim to experience the phenomenology associated with an extra limb and newly located bodily sensations provide an aid to such imaginings (Halligan et al., 1993).

A necessary truth about the hypothetical agent with acquaintance knowledge of the sensible content of others' suffering is that she would feel motivated to help. For it is impossible to have such knowledge without experiencing the sufferer's felt aversions

\footnotetext{
43 On the idea that desires, urges, and aversions show up in awareness with a valence and presentational phenomenology, see e.g., Ayded and Fulkerson (2019: p. 11):

Clearly, some sort of a desire-like state is involved somewhere in the phenomenology of sensory affect. When we have a pleasant sensation such as the taste of the ripe sweet strawberry, there is some sort of a tug that we feel toward the taste, we feel some kind of pull that makes us 'want to continue having the sensation'.... If there is any sense in which there is a kind of desire involved in affective experiences, it is a phenomenologically salient experiential desire.
}

\footnotetext{
44 Ahson Azmat observes in conversation that taking the sensed qualities constitutive of suffering to be known by the experiencing agent creates too wooden a gap between the agent and the sensible qualities involved in the experience. The gap feels wooden only because we do not ordinarily contemplate it. Reflecting on the self and the nature of pain, for example, I feel no inclination to identify myself with the phenomenology of pain. I feel or experience pain but am not to be identified with it.
} 
to her own pain, given that suffering of the morally urgent sort we've focused on constitutively involves felt aversion to pain. Accordingly, felt desires to mitigate other people's pain turn out to be constitutive of being fully knowledgeable. This implies that an agent's failure to be concerned about the suffering of others can always be explained as a form of ignorance: a reason that the morally indifferent cannot find motivation to help others is that they lack knowledge of what others experience when they suffer. ${ }^{45}$ And this epistemic explanation of moral failure needn't crowd out other, more familiar explanations, for example, one that appeals to a lack of empathy. ${ }^{46}$

A potential drawback of the proposal is that it seems to paint the radically amoral and agents of ordinary moral virtue with the same brush, insofar as neither have nor could feasibly acquire knowledge of the relevant sort. This would be an undesirable implication if moral commonsense assumed not just that there is virtue-entailing knowledge, but that everyday forms of other regard are based on that knowledge. However, if morality turns out to be very demanding - for example, requiring that we always act to minimize suffering - then it is a feature of the view, not a bug, that the sort of knowledge that is sufficient for ideal moral compliance turns out to be generally out of reach. That said, since direct acquaintance with the sensible content of others' experiences is clearly not a prerequisite for showing some concern for others, it would be to the proposal's credit if we can use it explain why the morally conscientious do better in epistemic terms than the radically amoral for reasons related to the knowledge neither possess.

We can sketch how an explanation of ordinary moral virtue might run, although a serious treatment of the question would take us too far afield. Moral philosophers sometimes describe empathy and compassion as epistemic goods, though usually in terms of the representational accuracy of such states. ${ }^{47}$ Knowledge by acquaintance suggests an alternative account of the epistemic good of empathy, one that begins with

\footnotetext{
45 A worry might be raised that all-encompassing knowledge of the sort achieved by an epistemically ideal agent must involve acquaintance with a wide range of experiences, including those of psychopathic or cruel agents, and so, at best, a fully knowledgeable agent experiences felt desires to mitigate the pains of others as well as felt desires to promote such pain. However, upon reflection it seems unlikely that desires to promote other people's pain could persist in a state of maximal acquaintance. Desires unrelated to pain tend to lose their urgency in the grip of pain and suffering. There is an introspectable asymmetry between pain (and the felt desire to stop it) and desires unrelated to pain mitigation. Moreover, desires to inflict suffering on others likely have as their condition a lack of acquaintance with what others experience when they suffer. So, it is not all that implausible to suppose that full acquaintance entails robust felt concern for mitigating suffering generally.

46 To borrow an example from Bernstein (2016), the fact that Sam didn't win the Fields Medal might be explained by appeal to the impossibility of proving the proposition Sam was trying to prove; but it wouldn't crowd out other explanations for the same fact, like the fact that Susan proved a longstanding mathematical conjecture. Likewise, an explanation of moral failure in terms of the impossibility of knowing what others experience when they suffer is compatible with other explanations-e.g., that morally indifferent agents lack the desire to live a life that's justifiable to others.

47 For a history of this idea, see Marshall (2019). On Marshall's own proposal, the good of compassion involves having representationally accurate experiences. The compassionate agent experiences distress at others' suffering and so "compassionate reactions... significantly resemble pains like the [sufferer's], and a representation's resembling pain is necessary and sufficient for it to reveal pain, and so for letting the subject know what the property is like" (p. 68). An objection to Marshall's view is that knowing what pain is like does not necessarily require occurrently experiencing distress (Lerner 2019). Moreover, there are some obvious ways in which compassionate distress is not representationally accurate in relation to other people's pain. For example, painful experiences have a self-referential character as reflected in the imperatives ("stop
} 
the observations that (a) epistemically virtuous agents aim to approximate knowledge in the face of what is unknowable; and (b) empathic agents, arguably, have a means of approximating acquaintance knowledge of the sensible content of others' suffering. For empathy involves a kind of distress and, so, delivers a form of knowledge by acquaintance — namely, of one's own pain — that is difficult to bear. The acquaintance knowledge involved in empathy, by virtue of being unpleasant, offers a glimpse of what it would be like to have acquaintance knowledge of what others experience when they suffer. Moreover, empathic agents demonstrate an important epistemic virtue-intellectual courage or the fortitude to know hard reality by approximation-when, instead of tending to their own distress, they endeavor to alleviate the suffering of others. ${ }^{48}$ For this is a choice that does not impair their ability to approximately know what others experience. The details of such an account would need filling out, including the assumptions about empathy, approximate knowledge, and epistemic virtue that I do not claim to have motivated here. ${ }^{49}$ But the limited point for present purposes is that the argument of this section does not rule out an epistemic vindication of ordinary moral concern. ${ }^{50}$

Even with the question of ordinary virtue bracketed, we have made ethical progress insofar as we've succeeded in showing (a) that our perspective on the world is epistemically incomplete, and (b) that the epistemic defect in our perspective is always an available explanation of inadequate concern for the suffering of others. The argument, summarized, relies on two major assumptions:

(1) acquaintance is knowledge, and

(2) we are not acquainted with the sensible content of others' suffering, along with a relatively minor assumption:

(3) the sensible content of suffering includes felt aversions to pain.

It follows from these assumptions that if an agent had complete knowledge of what others experience when they suffer, she would feel motivated to show concern. The

\section{Footnote 47 continued}

this pain!") sometimes used to model their representational content (cf. Klein 2007). When I am pained at another's suffering but moved to mitigate my own distress by shifting attention away from the distressing state of affairs, I have an experience that accurately represents the self-referential character of other people's pain. Marshall (2019, p. 78) acknowledges the worry in a footnote (fn. 47) but dismisses it, to my mind, too cursorily. An account of the epistemic good of empathy and compassion in terms of acquaintance knowledge along the lines discussed below avoids these challenges, although a full defense of the view sketched here is beyond the scope of this paper. I limit myself to pointing out that acquaintance knowledge provides an alternative means of accounting for the value of empathy and compassion in epistemic terms.

48 On intellectual courage as the ability to respond appropriately to threats to one's epistemic wellbeing, including such threats as the temptation to believe what is convenient, see Roberts and Wood (2007).

49 A systematic defense of a proposal along these lines is the subject of follow-up work (manuscript on file with the author).

50 There might be other ways of explaining ordinary virtue based on what we've established. Several moral philosophers have defended principles that entail practical reasons to behave as our epistemically ideal selves would (cf. Williams 1981; Smith 1994; Markovits 2015). Epistemic idealization in ethics has traditionally been construed in terms of correcting an agent's false beliefs or giving her true beliefs. The standard idealizations neglect to consider epistemic improvements driven by an agent's acquaintance knowledge. Such improvements, even when they are physically impossible for ordinary agents, are at least conceivable. 
connection derives from an essential feature of the scenario of being acquainted with the sensible content of others' suffering: it is, constitutively, a scenario in which one feels aversion towards the pains of others just as they do.

$A \Rightarrow K$ thus plays an essential role in vindicating a widely shared moral conviction that there is a connection between the epistemic good and concern for the suffering of others. The vindication relies on premises that are defensible and that ordinary moral agents should easily grasp. This in turn suggests that a commitment to acquaintance being knowledge is likely implicit in the moral reasoning of agents, a fact which of itself counts in favor of $A \Rightarrow K$ by revealing the principle's embeddedness in our ordinary ways of thinking.

\section{Objections and replies}

So far, the case for $A \Rightarrow K$ has been entirely positive. There might be independent reasons for doubting that acquaintance is knowledge. In this final section, I consider two objections that might be seen as especially significant, beginning with some general observations about the case against the principle.

First, even if there is some decisive reason to think acquaintance couldn't be knowledge, we've established that the denial is costly. It deprives us of a plausible explanation of why Chalmers' imagined Eden exhibits manifest epistemic appeal, why the knowledge Mary gains is elusive and persists fully only as long as her state of acquaintance does, and why acquaintance satisfies the functional role of knowledge in the case of evaluative beliefs, inferences, and statuses. It deprives us, also, of justification for a familiar claim about the connection between knowledge and other regard that many find intuitive. All of this can be admitted even if some reason to reject $A \Rightarrow K$ turns out to be decisive.

Second, there is a perfectly general response to a class of objections that take the following form. It is a conceptual truth that knowledge involves $X$. Acquaintance does not involve $X$. Therefore, acquaintance is not knowledge. E.g., one might insist that the concept of knowledge is the concept of a mental state that is evaluable for truth, or that no state that isn't a belief state could possibly satisfy the ordinary concept of knowledge. Since acquaintance is infallible, cannot be evaluated for truth, and isn't a belief state, acquaintance is not knowledge.

Such objections seem to mistake a conceptual truth about one of the forms of knowledge, like propositional knowledge, for a more general conceptual truth about knowledge. It's true that propositional knowledge involves belief. But it is hardly clear that practical 'know-how' does. Intuitions about the ordinary concept should be tested against the great variety of relations tracked by our ordinary knowledge-talk (Farkas, 2019). And, in any event, we aren't so concerned with whether acquaintance fits the ordinary concept of knowledge perfectly. The question of interest is whether acquaintance exhibits final epistemic value, the kind of value exhibited by paradigm instances of knowledge, which is a substantive normative question. So, any criticism of the thesis that invokes some putatively essential feature of knowledge-bearing mental states (truth-aptness, fallibility) needs to explain why the feature is essential for a state to exhibit non-instrumental epistemic value. 
(i) The myth of the given

The importance of grounding objections to $A \Rightarrow K$ in considerations of epistemic value can be illustrated by way of two substantive concerns one might have about the thesis. The first is associated with Sellars (1968) under the rubric of the "myth of the given' and has been developed more recently by McDowell (2008). Sellars and McDowell suggest that our perceptual encounters with the world already involve the operation of our conceptual capacities to categorize and distinguish, and our abilities to have thoughts about our experiences. In other words, there are no pre-conceptual, prepropositional cases of perceptual experience. Our capacities for propositional thought bestow form and unity on our perceptual experiences, without which such experiences would be unrecognizable. E.g., propositional thoughts of the form there is an object in my visual field might be "operative in experiencing itself, not just in judgments in which we respond to experience" (McDowell, 2008: p. 258; cf. Byrne, 2009, Glüer, 2009). ${ }^{51}$

In present terms, the worry is that our failure to produce cases of epistemically relevant acquaintance which do not involve propositional thoughts casts doubt on the assumption that acquaintance by itself exhibits final epistemic value. Stripped of propositional content, perceptual encounters seem epistemically irrelevant. Cases of attentional and change blindness might be marshalled as evidence in support of the claim that raw acquaintance, if possible, is of little to no epistemic value.

These observations do not establish that acquaintance, considered apart from propositional attitudes, cannot be knowledge or exhibit final epistemic value. At best, they establish that acquaintance cannot exhibit final epistemic value without an agent having and deploying capacities for propositional thought. Here, we can help ourselves to a familiar distinction between final and intrinsic value (Korsgaard, 1983). A state has intrinsic value when its value is constituted entirely by its intrinsic non-relational properties, whereas a state has final value just in case it is the ultimate object of our concern. A beautiful painting has final value, but if the existence of aesthetic value is contingent on there being perceivers around to find paintings desirable, then the existence of perceivers enables the ultimate value of a beautiful painting (cf. Schroeder 2007). ${ }^{52}$ The object of ultimate aesthetic concern remains the painting, not the fact that there are perceivers around to appreciate it. Likewise, if propositional knowledge and various attentional acts enable acquaintance's final epistemic value, this would explain why a raw encounter with a volume of redness can hardly be described as an epistemically valuable state. Acquaintance exhibits value once it is embedded in a more complex set of knowing attitudes of the agent.

\footnotetext{
51 McDowell has distanced himself from the view he once espoused-namely, that experience necessarily involves propositional content: "Avoiding the Myth requires capacities that belong to reason to be operative in experiencing itself not just in judgments in which we respond to experience. How should we elaborate this picture? I used to assume that to conceive experiences as actualizations of conceptual capacities, we would need to credit experiences with propositional content, the sort of content judgments have" (2008, p. 3). And "according to my old assumption, experiences have the same kind of content as beliefs." McDowell's updated view is that experiences essentially involve conceptual recognition capacities if not propositional content.

52 Schroeder's (2007) distinction between what counts as the normative reason for an attitude and the necessary background conditions for the existence of the reason is helpful here.
} 
Accordingly, a proponent of $A \Rightarrow K$ needn't subscribe to the 'myth of the given.' Perhaps all cases of acquaintance knowledge involve the belief that one is acquainted with some existing thing. So long as it remains possible to conceptually tease apart acquaintance from accompanying propositional attitudes, which seems apparent from the very scenarios designed to motivate the point about stripped-down perceptual encounters being epistemically irrelevant, we can make sense of the claim that acquaintance is knowledge (and finally valuable as such), notwithstanding the fact that acquaintance wouldn't be so without our having and deploying capacities for propositional thought during acquaintance.

(ii) The unity of knowledge

Acquaintance knowledge should pattern with other more familiar forms of knowledge, like propositional knowledge and know-how. ${ }^{53}$ Yet it is hard to see how these three forms of knowledge could be informatively subsumed under a genus or usefully categorized together (Farkas, 2019; Fumerton, 1995). It is a mark against the view that it portrays a category as philosophically important as 'knowledge' as being gerrymandered.

The challenge can be illustrated using popular accounts of the unifying nature of knowledge. Knowledge is often described as a non-accidental cognitive achievement of the sort for which we deserve credit (Greco, 2003; Sosa, 2001). Zagzebski (2003) compares knowledge to "points earned in a game" and contrasts it with mere "blessings of good fortune." Propositional knowledge is the non-accidental possession of a truth. Practical know-how involves non-accidental success in mentally guided action (Ryle, 1949). Both represent non-lucky achievements which make us creditworthy.

The acquaintance theorist struggles with such accounts of the essence of knowledge. Not just any cognitive achievement warrants praise or credit, and it is doubtful that acquaintance knowledge earns us any credit. We know a great many objects in the world simply by virtue of being perceiving agents. ${ }^{54}$ In a clear enough sense, the epistemic value realized through acquaintance isn't a product of our deliberate choices or capacities to infer or reason. It amounts to an achievement of nature acting independently of our deliberate cooperation. While the attentional focus that is arguably necessary for acquaintances to have value might be effortful, we are effortlessly acquainted with the sensible qualities.

For what it is worth, it seems to me a mistake to think of the good of knowledge generally, and that of acquaintance knowledge, in particular, as fruitfully analogized to points earned in a game. The value of knowledge, like the value of pleasure and social connections, would seem just as high whether we have to work for it or not. What is needed is an account of final epistemic value that can explain what knowledgebearing mental states have in common. The possibility I'll defend briefly in closing is that it is a basic feature of the epistemic domain, not necessarily explicable in non-normative terms, that the mental states involved in acquaintance, know-how, and factual knowledge exhibit a common type of final value. It should be noted that it is

\footnotetext{
53 Moreover, if propositional knowledge is the paradigm case, an account of knowledge's unity should take features of propositional knowledge as the explanatory starting point.

54 The normally sighted and sensate possess much of epistemic worth that wouldn't be impaired even if we turned out to be brains in vats or radically deceived by evil demons.
} 
often and in general difficult to say why individual goods are related in their goodness. Social relationships, living a life that is justifiable to others, and the elimination of suffering all seem related to the final moral good. But it is hard to give an informative answer to the question of what they have in common. Likewise, pleasure, personal achievement, and friendship, all seem relevant to an agent's final prudential good, but providing a unifying theory of this species of value turns out to be challenging. Still, it would be unsatisfying to leave it at that, to simply insist without argument that acquaintance exhibits the same type of value as propositional knowledge.

The assumption of shared value can be defended indirectly. I've already offered several arguments for assuming $A \Rightarrow K$. Additional support may be found in the judgments and motivations of knowledge-valuing agents. That agents tend to jointly value $A$ and $B$ counts as some defeasible evidence that the two are valuable in the same way. In the opening lines of the Metaphysics, Aristotle notes "the delight we take in our senses; for even apart from their usefulness they are loved for themselves" [1.1: 980a22-28]. The love of truth, acquaintance, and practical know-how may well have a common motivational basis (cf. James, 1896). ${ }^{55}$ A systematic defense of the claim that things finally and jointly desired exhibit the same value (or involve an appreciation of the same type of evaluative fact) would take us too far afield. But it is eminently defensible on meta-normative grounds. ${ }^{56}$

Another structural feature which points to an evaluative similarity is that the various epistemic goods enter into value-enabling relations with one another. We've already noted that propositional attitudes may be necessary for acquaintance to exhibit noninstrumental value, but so might knowing how to direct attention to features of one's mental life. Symmetrically, propositional knowledge quite plausibly depends on (is enabled by) acquaintance. The deliverances of the senses enable various forms of propositional knowledge, conferring epistemic value on true beliefs formed as a result of such acquaintances (cf. Ayers, 2019; Byrne, 2016). And dispositional tendencies would hardly be worthy of being called 'knowledge-how' if the agent lacked the capacity to experience conscious control (felt intentions) or form propositional thoughts (cf. Williamson, 2000). These relations of value-enablement, observed in other evaluative domains as well, ${ }^{57}$ point towards an evaluative similarity: acquaintances, propositional attitudes, and abilities together enable an agent to participate in the epistemic good.

Admittedly, this final analysis has been breezy. Much more needs to be said before the possibilities laid out can be responsibly embraced. However, the central aim of this paper wasn't to overcome all doubts about acquaintance being knowledge, but to develop a novel positive case for it based on a broad range of considerations. The limited purpose of this final section has been to show that there are overlooked

\footnotetext{
55 William James locates our commitment to the truth and aversion to falsity in our passionate natures. The claims here are compatible with a Jamesian (or better: 'Humean') account of epistemic normativity.

56 Desire-like attitudes and evaluative judgments are viewed as intimately related by (among others) metaethical quasi-realists (cf. Blackburn 1984) and evaluative intuitionists of the sort who treat desire and affect as normative 'seemings' or perceptions of bona fide value (cf. Johnston 2001; Scanlon 1998). My claim that things jointly and finally desired exhibit the same value can be motivated based on such accounts of normativity construed as fully general to include epistemic normativity.

57 Compare an analogous phenomenon in the prudential case: the various prudential goods, like pleasure and friendship, exhibit final value together and enter into symmetric value-enabling relations.
} 
responses to well-known objections that seem sufficiently promising to warrant further development given the striking attractiveness and theoretical usefulness of our guiding hypothesis.

Acknowledgements A special thanks to Rachel Schutz for many conversations on acquaintance and for insightful comments on multiple drafts. I received helpful feedback from three anonymous referees for Synthese, whose comments significantly improved the paper. I am grateful, also, to Carlotta Pavese, Matt Duncan, Rachana Kamtekar, David Enoch, Julia Markovits, Uriah Kriegel, Sebastian Köhler, David Chalmers, Katalin Farkas, Andrei Marmor, and Ahson Azmat for their comments on earlier drafts; and to participants at a seminar-workshop on emergence in the natural sciences at the University of Lisbon (2021), where I presented some of the core ideas of the paper.

\section{References}

Aydede, M., \& Fulkerson, M. (2019). Reasons and theories of sensory affect. In D. Bain, M. Brady, \& J. Corns (Eds.), The philosophy of pain: Unpleasantness, emotion, and deviance (pp. 27-59). Routledge. Ayers, M. (2019). Knowing and seeing: A groundwork for a new epistemology. Oxford University Press.

Balog, K. (2012). In defense of the phenomenal concept strategy. Philosophy \& Phenomenological Research, $84,1-23$.

Bernstein, S. (2016). Omission Impossible. Philosophical Studies, 173(10), 2575-2589.

Blackburn, S. (1984). Spreading the word. Oxford University Press.

Brewer, B. (2006). Perception and content. European Journal of Philosophy, 14, 165-181.

Brewer, B. (2019). Visual experience, revelation, and the three Rs. In J. Knowles \& T. Raleigh (Eds.), Acquaintance: New essays. Oxford University Press.

Brogaard, B. (2011). Color experience in blindsight? Philosophical Psychology, 24(6), 767-786.

Byrne, A. (2009). Experience and content. The Philosophical Quarterly, 59, 429-451.

Byrne, A. (2016). The epistemic significance of experience. Philosophical Studies, 173, 947-967.

Carroll, L. (1895). What the tortoise said to achilles. Mind, 4, 278-280.

Carruthers, P. (2004). Suffering without subjectivity. Philosophical Studies, 121, 99-125.

Chalmers, D. (2006). Perception and the fall from Eden. In T. S. Gendler \& J. Hawthorne (Eds.), Perceptual experience (pp. 49-125). Oxford University Press.

Chalmers, D. (2018). The meta-problem of consciousness. Journal of Consciousness Studies, 25, 6-61.

Conee, E. (1994). Phenomenal knowledge. Australasian Journal of Philosophy, 72, 136-150.

Crane, T. (2012). Review: Tye on acquaintance and the problem of consciousness. Philosophy \& Phenomenological Research, 84, 190-198.

Duncan, M. (2020). Knowledge of things. Synthese, 197, 3559-3592.

Fagin, R., \& Halpern, J. (1988). Belief, awareness, and limited reasoning. Artificial Intelligence, 34, 39-76.

Farkas, K. (2019). Objectual knowledge. In J. Knowles \& T. Raleigh (Eds.), Acquaintance: New essays. Oxford: Oxford University Press.

Fumerton, R. (1995). Metaepistemology and skepticism. Rowman and Littlefield.

Gertler, B. (2012). Renewed Acquaintance. In D. Smithies \& D. Stoljar (Eds.), Introspection and consciousness (pp. 89-123). Oxford University Press.

Glüer, K. (2009). In defence of a doxastic account of experience. Mind \& Language, 24, 297-373.

Greco, J. (2003). Knowledge as credit for true belief. In M. DePaul \& L. Zagzebski (Eds.), Intellectual virtue: Perspectives from ethics and epistemology (pp. 111-134). Clarendon Press.

Grzankowski, A., \& Tye, M. (2019). What acquaintance teaches. In J. Knowles \& T. Raleigh (Eds.), Acquaintance: New essays. Oxford University Press.

Haidt, J. (2001). The emotional dog and its rational tail: A social intuitionist approach to moral judgment. Psychological Review, 108, 814-834.

Halligan, P., Marshall, J., \& Wade, D. (1993). Three arms: A case study of supernumeral phantom limb after right hemisphere stroke. Journal of Neurology, Neurosurgery, and Psychiatry., 56, 149-166.

Hauser, M. D., Cushman, F., Young, L., Jin, R.-X., \& Mikhail, J. (2007). A Dissociation between moral judgments and justifications. Mind \& Language, 22, 1-21.

Hintikka, J. (1991). Knowledge and the known. Springer.

Howell, R. J. (2013). Consciousness and the limits of objectivity. Oxford University Press. 
Hume, D. (1739-1740). A treatise of human nature. In Norton, D. F. \& Norton, M. J. (Eds.), New York: Oxford University Press. 2000.

Iaquinto, S., \& Spolaore, G. (2019). Outline of a logic of knowledge of acquaintance. Analysis, 72, 59-61. Jackson, F. (1982). Epiphenomenal qualia. Philosophical Quarterly, 32, 127-136.

James, W. (1896). The will to believe. The New World, 5, 327-347.

Johnston, M. (2001). The authority of affect. Philosophy and Phenomenological Research, 63(1), 181-214. Johnston, M. (2004). The obscure object of hallucination. Philosophical Studies, 120(1-3), 113-183.

Johnston, M. (2011). On a neglected epistemic virtue. Philosophical Issues, 21(1), 165-218.

Klein, C. (2007). An imperative theory of pain. Journal of Philosophy, 104(10), 517-532.

Korsgaard, C. (1983). Two distinctions in goodness. Philosophical Review., 92, 169-195.

Kvanvig, J. (2003). The value of knowledge and the pursuit of understanding. Cambridge University Press. Leite, A. (2008). Believing one's reasons are good. Synthese, 161(3), 419-441.

Lerner, A. (2019). Review of 'Compassionate Moral Realism,' by Colin Marshall. Notre Dame Philosophical Reviews.

Lewis, D. (1990). What experience teaches us. In W. Lycan (Ed.), Mind and cognition: A reader. Blackwell's. Mackie, J. L. (1977). Ethics: Inventing right and wrong. Penguin Books.

Maddy, P. (1988). Believing the axioms. Journal of Symbolic Logic, 53(2), 481-511.

Makinson, D. (2003). Ways of doing logic: What was new about AGM 1985. Journal of Logic and Computation, 13, 5-15.

Markovits, J. (2015). Moral reason. Oxford University Press.

Marshall, C. (2019). Compassionate moral realism. Oxford University Press.

McDowell, J. (2008). Avoiding the myth of the given. In J. Lindgard (Ed.), John McDowell: Experience, norm, and nature. Blackwell.

Moser, P. (1989). Knowledge and evidence. Cambridge University Press.

Moore, G. E. (1903). Principia ethica. Cambridge University Press 1962.

Moore, G. E. (1910). Sense data. Reprinted in T. Baldwin (Ed.), Selected writings. 1993. Routledge.

Nichols, S. (2004). Sentimental rules: On the natural foundations of moral judgement. Oxford University Press.

Price, H. (1950). Perception (2nd ed.). Methuen.

Raineri, C. (2021). What's so Naïve about Naïve Realism? Philosophical Studies.

Raymont, P. (1999). The know-how response to Jackson's knowledge argument. Journal of Philosophical Research, 24, 113-126.

Roberts, R. C., \& Wood, W. J. (2007). Intellectual virtues: An essay in regulative epistemology. Oxford University Press.

Robinson, H. (1994). Perception. Routledge.

Russell, B. (1910). Knowledge by acquaintance and knowledge by description. Proceedings of the Aristotelian Society, 11, 108-128.

Russell, B. (1911). Knowledge by acquaintance and knowledge by description. Proceedings of the Aristotelian Society, 11, 108-128.

Russell, B. (1912). The Problems of Philosophy. Oxford University Press.

Ryle, G. (1949). The concept of mind. Hutchinson.

Scanlon, T. (1998). What we owe to each other. Harvard University Press.

Schroeder, M. (2007). Slaves of the Passions. Oxford University Press.

Sellars, W. (1968). Empiricism and the philosophy of mind. Routledge.

Skow, B. (2011). Experience and the passage of time. Philosophical Perspectives 25: Metaphysics, pp. 359-387.

Smith, M. (1994). The moral problem. Wiley-Blackwell.

Sosa, E. (2001). For the love of truth. In A. Fairweather \& L. Zagzebski (Eds.), Virtue epistemology. Oxford University Press.

Tye, M. (2000). Knowing what it is like: The ability hypothesis and the knowledge argument. In G. Preyer (Ed.), Reality and humean supervenience: Essays on the philosophy of David Lewis. Rowman \& Littlefield.

Tye, M. (2006). Another look at representationalism about pain. In M. Aydede (Ed.), Pain: New essays on its nature and the methodology of its study. MIT Press.

Tye, M. (2009). Consciousness revisited: Materialism without phenomenal concepts. MIT Press.

Williams, B. (1981). Moral luck. Cambridge University Press.

Williamson, T. (2000). Knowledge and its Limits. Oxford University Press. 
Zagzebski, L. (2003). The search for the source of the epistemic good. Metaphilosophy, 34, 12-28.

Zagzebski, L. (2013). Omnisubjectivity: A defense of a divine attribute. Marquette University Press.

Publisher's Note Springer Nature remains neutral with regard to jurisdictional claims in published maps and institutional affiliations. 